\title{
Halogenating activity in an arctic population of brown macroalga Laminaria saccharina (L.) Lamour.
}

\author{
GABRIELE MEHRTENS and FRANK LATURNUS
}

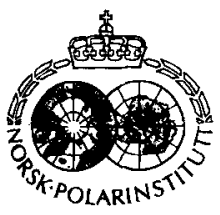

Mehrtens, G. \& Laturnus, F. 1997: Halogenating activity in an arctic population of brown macroalga Laminaria saccharina (L.) Lamour. Polar Research 16(1), 19-25.

Several sections of the thallus of an arctic population of brown macroalga Laminaria saccharina (L.) Lamour. were collected during April-June 1995, in the Kongsfjorden area at Ny-Aålesund, Svalbard and investigated for halogenating activity. Brominating activity was found in the blade only, while iodinating activity occurred in the whole thallus of $L$ saccharina. The highest activity occurred in the blade, while lower activity was detected in the stipe and holdfast. No evidence for chlorinating activity was found. Halogenating activity, which clearly depends on temperature, showed increasing rates with increasing temperatures between 5 and $35^{\circ} \mathrm{C}$.

G. Mehrtens, Alfred Wegener Institute for Polar and Marine Research, Columbusstrasse, D-27568 Bremerhaven, Germany; F. Latumus, University of Antwerp, Micro and Trace Analysis Centre, Universiteitsplein 1, B-2610 Wilrijk, Belgium.

\section{Introduction}

Biogenic halometabolites have a widespread occurrence in the environment and have been identified in organisms such as algae (Fenical 1975), bacteria and fungi (Neidleman \& Geigert 1986) and higher plants (Harper 1993). While biogenic fluorinated substances are very rare in the environment because they are synthesised only by some higher plants and bacteria (Neidleman \& Geigert 1986), chlorinated substances have been found abundantly, predominantly synthesised by terrestrial organisms. Of all biogenic halocarbons that have been identified in the marine environment, brominated compounds are dominant, mainly synthesised by marine macro algae (Moore 1977).

The functions of halocarbons in algal metabolism are still unknown. Since many of these substances have antifungal and antibacterial properties, halogenated compounds are thought to be part of the chemical defence system. There is substantial evidence that haloperoxidases are involved in the formation of biogenic halometabolites (Geigert et al. 1984; Soedjak \& Butler 1990). These enzymes catalyse the formation of organic substances by the oxidation of halides in the presence of hydrogen peroxide (Itoh et al. 1987). Haloperoxidases have been detected in a wide range of terrestrial and marine organisms (see Yamada et al. 1985; Wever et al. 1991; Harper 1993), and it has been shown that haloperoxidases are involved in the formation of halomethanes (Theiler et al. 1978; Walter \& Ballschmiter 1992).

Haloperoxidase activity has also been identified in various species of macroalgae growing in the arctic environments (Mehrtens 1994). Among the macroalgae investigated by Mehrtens (1994), an arctic population of brown alga Laminaria saccharina (L.) Lamour. showed high halogenating activity. It has recently been found that $L$. saccharina releases large quantities of volatile halocarbons (Laturnus 1996). This has received considerable interest because $L$. saccharina is a source of halogen radicals which are involved in various atmosphere photochemical reactions, for example the depletion of ozone (Solomon 1990; Peter 1994). Considering its ability to halogenate organic matter and its widespread occurence in the arctic environment (Dunton et al. 1982; Cross et al. 1987), L. saccharina can be an important source of halometabolites in the Arctic. However, little knowledge exists about the distribution pattern and physiological significance of haloperoxidases in arctic macroalgae.

In this study, whole plants of $L$. saccharina were divided into several sections to localise the activity of halogenating organic compounds in the alga thallus and to study the temperature dependence of halogenating activity. Previous standard enzyme assays for halogenating activity have been used at $25^{\circ} \mathrm{C}$, far above the temperatures of the environment of this sublittoral arctic popula- 
tion of L. saccharina. Data on localisation, temperature and $\mathrm{pH}$ dependence of halogenating activity in $L$. saccharina are presented and the role of halogenating activity in algal life and halocarbon production is discussed.

\section{Materials and methods}

Plant samples of $L$. saccharina were collected during the period April-June 1995, in the Kongsfjorden area at $\mathrm{Ny}$-Aålesund, Svalbard $\left(79^{\circ} \mathrm{N}, 12^{\circ} \mathrm{E}\right)$ at a depth of 4 to $8 \mathrm{~m}$ from a rubber-boat by a benthic alga sampling device (after Heath and Singleton 1988). The thalli of three different plants (length $100-240 \mathrm{~cm}$ ) were divided into 7 sections (see Fig. 1) and stored at $-20^{\circ} \mathrm{C}$ until analysis. These sections were assayed for halogenating activity and temperature dependence.

Due to the temperature sensitivity of the haloperoxidases all steps of algal preparation were carried out at temperatures below $5^{\circ} \mathrm{C}$. Each algal sample was washed twice with cold distilled water for 30 seconds and blotted with paper tissue. Two to four grams of each algal section were

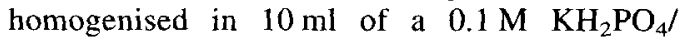
$\mathrm{K}_{2} \mathrm{HPO}_{4}$ buffer ( $\mathrm{pH} 6$ ) for $10 \mathrm{~min}$. After centrifugation, crude extracts were immediately used for activity measurements. Chlorinating and brominating activity was assayed spectrophotometrically by measuring the change in absorption at $278 \mathrm{~nm}$ (at $25^{\circ} \mathrm{C}, \epsilon=12.200 \mathrm{~cm}^{-1} \mathrm{M}^{-1}$ ) due to chlorinating or brominating of monochlorodimedone (MCD). The reaction solution contains $5 \mu \mathrm{l}$ $(0.3 \mu \mathrm{mol}) \mathrm{MCD}, 0.5 \mathrm{ml}(60 \mu \mathrm{mol}) \mathrm{KBr} / \mathrm{KCl}$ and $0.5 \mathrm{ml}$ crude extract was added to $1.5 \mathrm{ml}$ $(300 \mu \mathrm{mol})$ of buffer. A $0.2 \mathrm{M} \mathrm{KH} \mathrm{PO}_{4} / \mathrm{K}_{2} \mathrm{HPO}_{4}$ buffer was used with varying $\mathrm{pH}$ values from 4 to 7 for determination of the $\mathrm{pH}$ dependence on the brominating/chlorinating activity. The reaction was started by adding $0.5 \mathrm{ml}(6 \mu \mathrm{mol})$ hydrogen peroxide to the reaction mixture. Reference mixtures contained all solutions without MCD. Blank tests were performed at $\mathrm{pH}$ optimum without adding hydrogen peroxide to the reaction mixture.

Peroxidation of iodide was determined spectrophotometrically by measuring the formation of triiodide at $350 \mathrm{~nm}\left(25^{\circ} \mathrm{C}, \epsilon=26.400 \mathrm{~cm}^{-1} \mathrm{M}^{-1}\right)$. The reaction solution contained $1.9 \mathrm{ml}(300 \mu \mathrm{mol})$ $\mathrm{KH}_{2} \mathrm{PO}_{4} / \mathrm{K}_{2} \mathrm{HPO}_{4}$ buffer at $\mathrm{pH}$ optimum of the

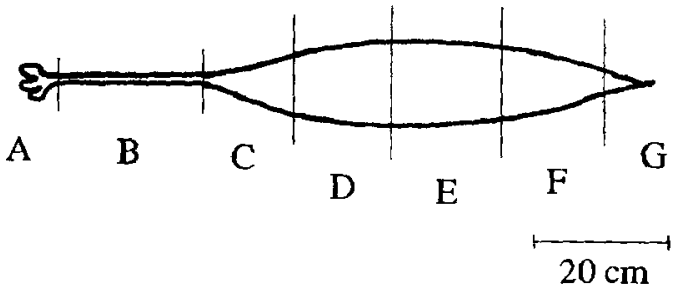

Fig. 1. Thallus parts of an arctic population of brown macroalga Laminaria saccharina (L.) Lamour, investigated in this study: A - holdfast, B - stipe-lower part, C - stipe-upper part, D blade-lower part, $\mathrm{E}$ - blade-lower middle part, $\mathrm{F}$ - blade upper middle part, $\mathrm{G}$ - blade-upper part.

brominating activity, $0.5 \mathrm{ml}(15 \mu \mathrm{mol}) \mathrm{KI}$ and $0.5 \mathrm{ml}$ crude extract. The reaction was started by adding $0.1 \mathrm{ml}(12 \mu \mathrm{mol})$ hydrogen peroxide. The reference contained no hydrogen peroxide. Blank tests were measured without the crude extract to determine oxidation of iodide by hydrogen peroxide (Mehrtens 1994). Temperature dependencies of halogenating activities were investigated using a thermostatic regulated cell. The spectrophotometric assays were done by varying the temperature in the cell from 5 to $35^{\circ} \mathrm{C}$ and measuring the change in absorption at $278 \mathrm{~nm}$ and $350 \mathrm{~nm}$, respectively.

One unit (U) of enzyme activity is defined for chlorination/bromination as the amount of enzyme capable of catalysing the halogenation of 1: mol monochlorodimedone per minute (Morris \& Hager 1966), and for iodination the amount of enzyme that catalyses the halogenation of $1 \mu \mathrm{mol}$ hydrogen peroxide per minute (Vilter et al. 1983). All chemicals were commercial products of analytical grade (p.a.). Monochlorodimedone was purchased from Sigma, Deisenhofen, and dissolved in ethanol. Ultraviolet spectras were recorded with a Spectrophotometer UVIKON 810 from Beckmann, Germany.

Spectrophotometric measurements of enzyme activity are a commonly used method for the determination of haloperoxidase activity in algae (Yamada et al. 1985). In crude extracts, unknown enzymic and chemical mechanisms can influence the reaction. Therefore, the detected activity is mentioned as halogenating activity only. The performance of blank tests was necessary to see whether a change in adsorbence already occurred without adding the oxidizing agent or crude extract. For the brominating activity, no changes of adsorbence were observed for any of the 
Fig. 2. Brominating and iodinating activity detected along the thallus of three different plants of an arctic population of brown macroalga Laminaria saccharina (measured at $25^{\circ} \mathrm{C}$ and $\mathrm{pH} 6$ ). A - holdfast, B - stipe-lower part, C - stipe-upper part, D blade-lower part, E - bladelower middle part, $\mathrm{F}$ - blade upper middle part, $\mathrm{G}$ - bladeupper part. Values are $\mathrm{mU} \mathrm{g}^{-1}$ wet algal weight as mean of triplicates \pm standard deviation.

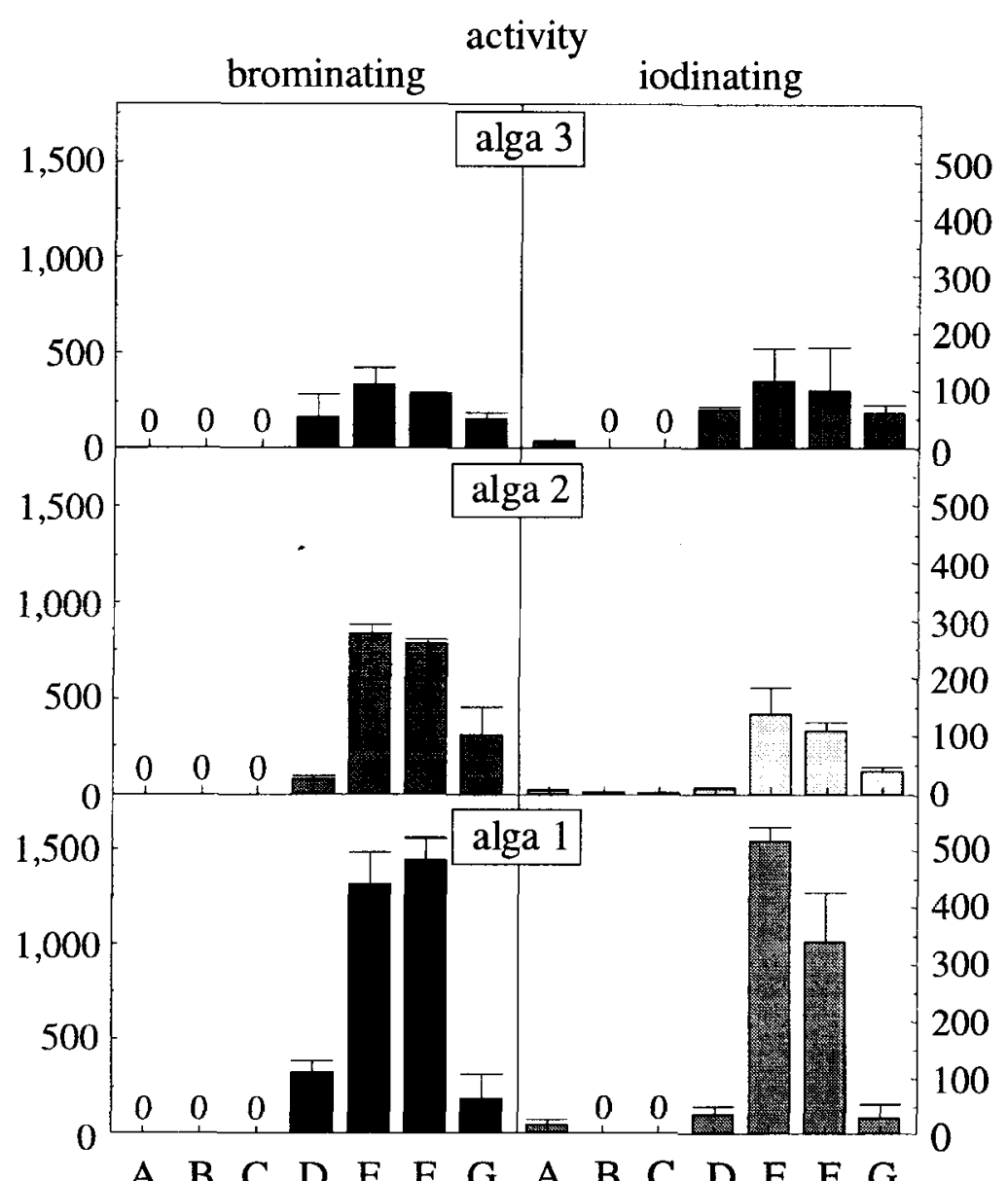

A B C D E F G A B C D E F G blanks. However, for the iodinating activity, blanks in the range of $9-26 \%$ of the detected activity for the crude extracts were sometimes found. Appropriately, values of the iodinating activity determined after adding the crude extracts were corrected.

\section{Results}

The distribution pattern of halogenating activity detected in the thallus of the three different single plants of L. saccharina is shown in Fig. 2. Brominating activity was detected in the blade (sections D-G), but not in the holdfast (section A) and stipe (sections $\mathrm{B}$ and $\mathrm{C}$ ). Additionally, $\mathrm{pH}$ dependence of brominating activity in the blade was examined with a $\mathrm{pH}$ optimum for bromina- tion between 5 and 6 (Fig. 3). The pH-activity curves, however, exhibited plateaus with a less evident identification of the actual $\mathrm{pH}$ optimum. Brominating activity was not distributed homogeneously in the blade (Fig. 2). Higher halogenating activity was found in sections $E$ and $F$ of the blade than in the basal and distal sections D and G. This pattern of activity distribution was found for all single plants investigated. Although the distribution pattern of the iodinating activity in the blade was similar to that of the brominating activity, values were always lower than for the brominating activity (Fig. 2). Additionally, stipe and holdfast also showed iodinating activity, but with considerably lower values than found in the blade.

The influence of temperature on the halogenating activity in the thallus of $L$. saccharina is shown in Fig. 4. Both brominating and iodinating 


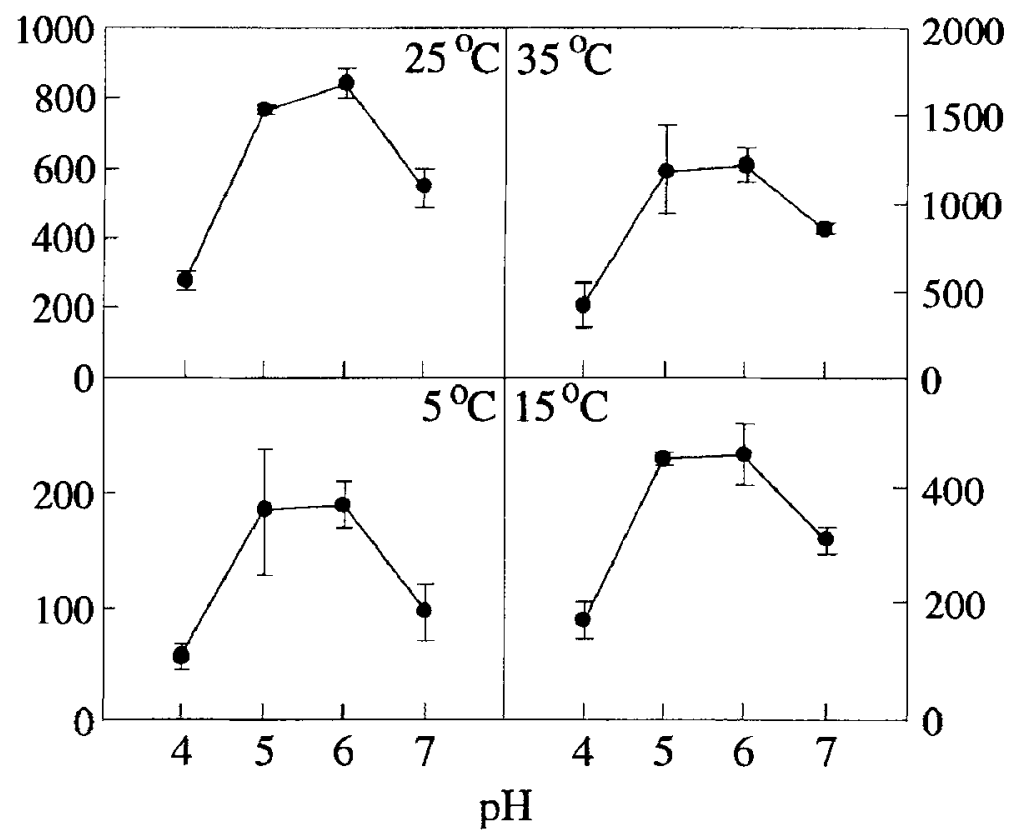

Fig. 3. $\mathrm{pH}$ dependence of the brominating activity measured in the lower middle part of a blade (section $\mathrm{E}$ ) of brown macroalga Laminaria saccharina (measured from alga no. 2, see Fig. 2) at different temperatures. Values are $\mathrm{mU} \mathrm{g}^{-1}$ wet algal weight as mean of triplicates \pm standard deviation. activity were strongly dependent on temperature. However, lower values for the iodinating activity compared to the brominating activity were found at all temperatures in all sections of the blade. Furthermore, the activity of iodinating organic compounds was detected in the stipe and holdfast, whereas brominating activity could not be measured in these parts of the plants, even at higher temperatures. An influence of the temperature on $\mathrm{pH}$ dependence of the halogenating activity could not be observed (Fig. 3). The pH optimum did not change due to increasing incubation temperature.

\section{Discussion}

The results clearly show the blade to be the most important and interesting part of the thallus for halogenating activity. Contrary to the blade, which possesses the highest brominating and iodinating activity, the stipe and holdfast showed no brominating activity, perhaps due to the absence or inhibition of the halogenating activity. All algae samples investigated showed different brominating and iodinating activity along the blade with high activity in sections $\mathrm{E}$ and $\mathrm{F}$ and lower values in sections $\mathrm{D}$ and $\mathrm{G}$. These variations in activity can depend on different metabolic activities in the various parts of the blade, possibly caused by the different ages of the single parts of a blade. Section D is the youngest part with the meristem while section $G$ is the oldest section of the alga (Fritsch 1961). Interesting is the strong variation in halogenating activity within the different single plants of $L$. saccharina investigated in this study (Fig. 2). Although the distribution pattern of the activity was the same in every single plant investigated, the values of activity are clearly different. The reasons for this variation are unknown, but it is possible that the different growth ages of the single plants are responsible.

The halogenating activity of the arctic $L$. saccharina studied is considerably influenced by temperature. As $L$. saccharina grows in the middle to lower sublittoral zone (3 to $15 \mathrm{~m}$ ), it is not subjected to large variations in temperature which occur for example in the tidal to upper sublittoral zone due to tidal fluctuations and weather conditions (Laturnus 1993). Hence, adaptations of halogenating activity to low temperatures were expected. Contrary to this, $L$. saccharina showed a higher halogenating activity 
Fig. 4. Temperature dependence of the brominating and iodinating activity detected along a thallus of brown macroalga Laminaria saccharina (measured from alga no. 2, see Fig. 2) measured at $\mathrm{pH} 6 . \mathrm{A}$ - holdfast, $\mathrm{B}$ - stipelower part, $\mathrm{C}$ - stipe-upper part D - blade-lower part, E blade-lower middle part, $\mathrm{F}$ blade upper middle part, $\mathrm{G}$ blade-upper part. Values are $\mathrm{mU} \mathrm{g}^{-1}$ wet algal weight as mean of duplicates. To avoid confusion, the variations of the duplicates are not included in the graphic.
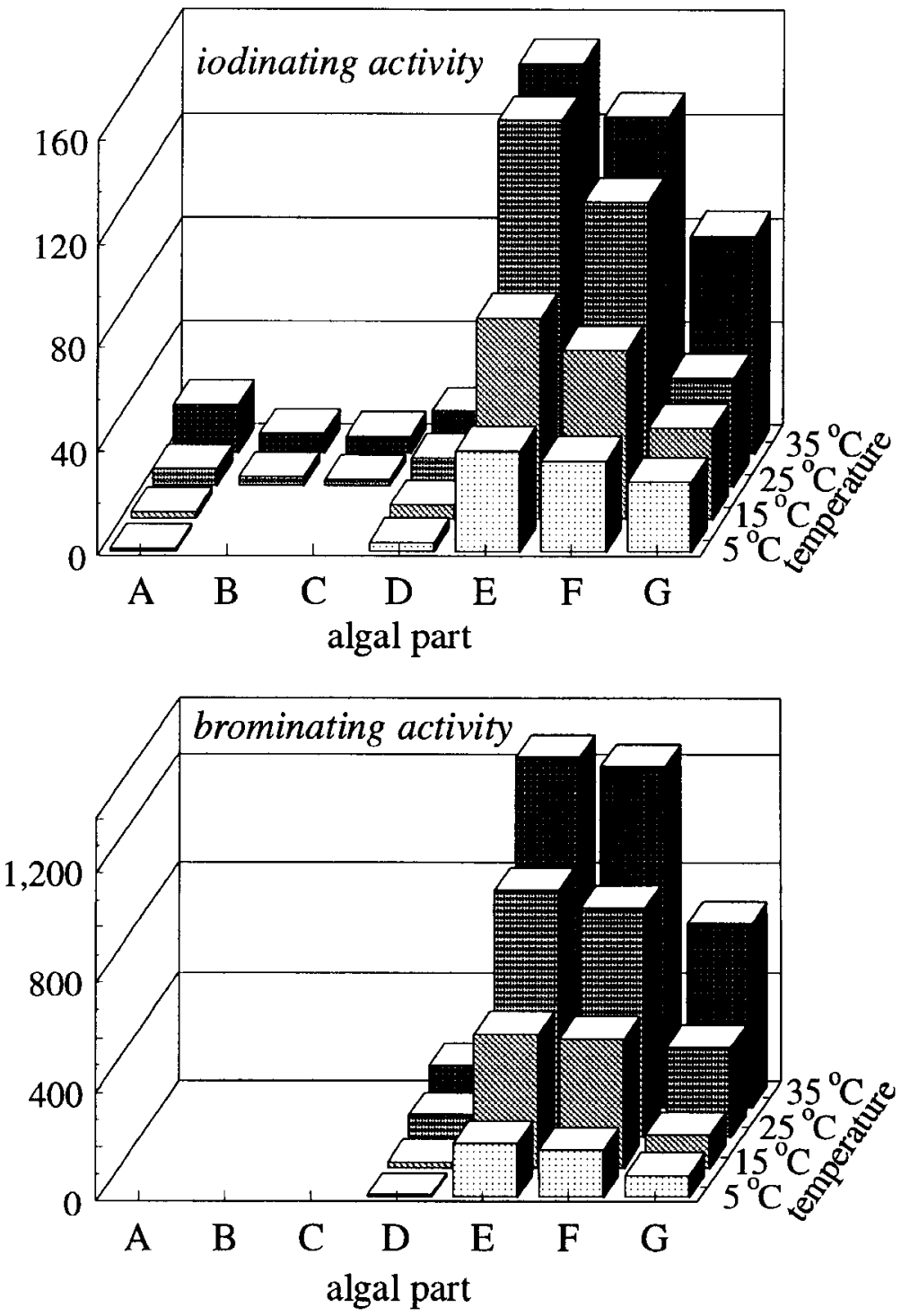

with increasing temperature far above the environmental conditions in this region. As ubiquitous in the northern hemisphere (Lüning 1990), $L$. saccharina also occurs in regions with higher environmental temperatures. Considering the higher production or activity of enzymes in termperate populations of $L$. saccharina, it might be supposed that temperate populations would exhibit a higher halogenating activity than arctic macroalgae populations, but this has yet to be verified.
Haloperoxidases are involved in the formation of halocarbons (Theiler et al. 1978; Neidleman \& Geigert 1986). However, the fate of halogenated substances inside the alga formed by haloperoxidases still remains unknown. Although places of high halogenating activity were localised and the potential of halogenating activity was determined, little can be said about the kind of halometabolites synthesised and their importance under natural conditions. Laturnus (1996) assayed the release of volatile halocarbons (VHOC) from different 


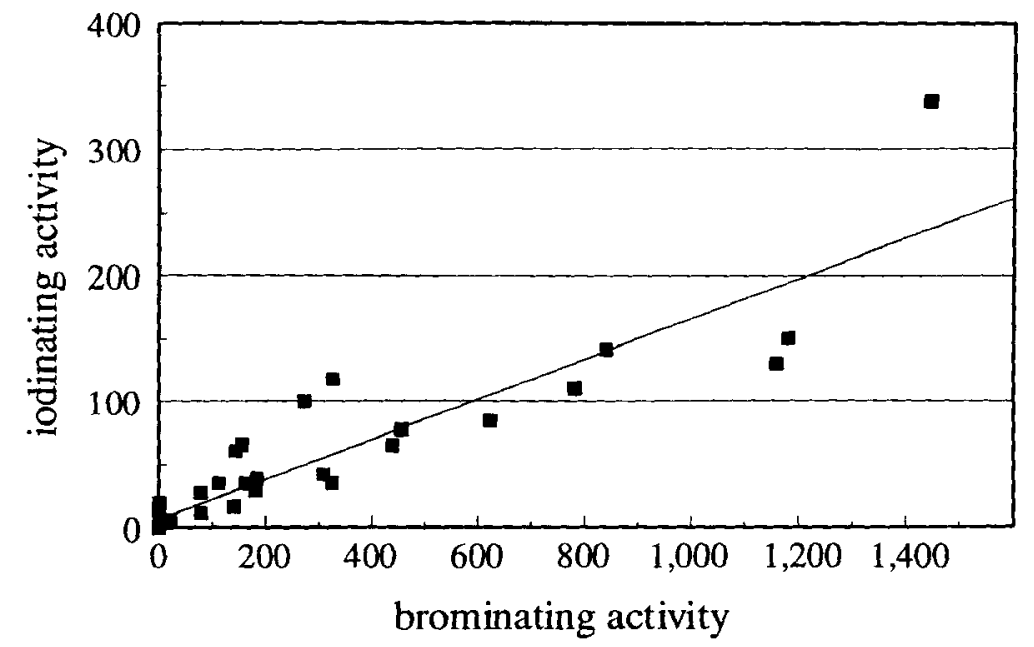

Fig. 5. Linear correlation $(\mathrm{r}=0.921, \mathrm{p}<0.001, \mathrm{n}=48)$ between the brominating and iodinating activity detected in the thallus of an arctic population of brown macroalga Laminaria saccharina. Values are $\mathrm{mU} \mathrm{g}^{-1}$ wet algal weight. sections of an arctic population of $L$. saccharina and found high concentrations emitted by the blade, whereas the stipe and the holdfast released only lower quantities. This clearly indicates that the places of VHOC release are identical with detected halogenating activity. Therefore, a formation of volatile halocarbons by haloperoxidases may be acceptable. Metabolic pathways by which VHOC such as bromoform are synthesised have been discussed by several authors (see Fenical 1975, Theiler et al. 1978, and Neidleman \& Geigert 1986). A correlation ( $p<0.001$ ) has been found for the brominating and iodinating activity (Fig. 5). Therefore, the occurrence of only a bromoperoxidase in $L$. saccharina may be possible.

Bromoperoxidases can catalyse the oxidation of bromine and iodine, but not the oxidation of chlorine (Geigert et al. 1984). De Boer et al. (1986) reported the presence of a vanadium (V)containing bromoperoxidase in a temperate population of $L$. saccharina (collected at Audresselle, France), which can be present also in the arctic population of $\dot{L}$. saccharina studied here. Wever et al. (1991) showed the localisation of bromoperoxidases on the thallus surface of the brown seaweed Ascophyllum nodosum (L.) Le Jol. and the release of hypobromous acid (HOBr) into seawater. Hypobromous acid, an extremely reactive species, reacts with organic matter and may be a major step in the formation of VHOC. Another pathway can be the intracellular bromi- nation of ketones present in algae, which decay via haloform reaction to polyhalomethanes (Theiler et al. 1978). Since volatile halocarbons are assumed to take part in the depletion of ozone in the arctic atmosphere (Finnlayson-Pitts et al. 1990 ), it is important to characterise the sources of these substances to estimate the biogenic contribution to the halocarbon burden in the Arctic.

The investigation of $L$. saccharina as a widespread distributed macroalgal species in the Arctic showed a possible influence of this alga on the halocarbon input into the arctic environment. High brominating and iodinating activity implicated in the formation of halocarbons were detected in the blade as the main part of the alga. An influence of temperature on the activity was observed as increasing temperature led to a higher brominating and iodinating activity. Furthermore, other factors such as the season, light conditions or algal age may also have non-negligible effects on the halogenating activity. Information on this field is, however, still scarce. Measurements of these parameters would contribute to understanding the role of macroalgae in producing and releasing halocarbons into the arctic environment.

Acknowledgements. - We are grateful to C. Wiencke for helpful comments on the manuscript and E. Levy who improved grammar and style. Special thanks to U. Wieschollek for assistance during the field work. Publication No 1267 of the Alfred Wegener Institute for Polar and Marine Research. 


\section{References}

Cross, W. E., Wilce, R. T. \& Fabijan, M. F. 1987: Effects of experimental release of oil and dispersed oil on Arctic nearshore macrobenthos. III. macroalgae. Arctic 40 , 211-219.

De Boer, B., Tromp, M. G. M., Plat, H., Krenn, G. E. \& Wever, R. 1986: Vanadium (V) as an essential element for haloperoxidase activity in marine brown algae: purification and characterization of a vanadium (V)-containing bromoperoxidase from Laminaria saccharina. Biochim. Biophys. Acta 872, 104-115.

Dunton, K. H., Reimnitz, B. \& Schonberg, S. 1982: An Arctic kelp community in the Alaskan Beaufort Sea. Arctic 35 , $465-484$

Fenical, W. 1975: Halogenation in Rhodophyta - A review. J. Phycol. 11, 245--259.

Finnlayson-Pitts, B. J., Livingston, F. E. \& Berko, H. N. 1990: Ozone destruction and bromine photochemistry at ground level in the Arctic spring. Nature (London) 343, 622-625.

Fritsch, F. B. 1961: The Structure and Reproduction of the Algae - Vol II. University Press, Cambridge. 939 pp.

Geigert, J., Neidleman, S. L., DeWitt, S. K. \& Dalietos, D. I. 1984: Haloniumion-induced biosynthesis of chlorifiated marine metabolites. Phytochem. 23, 287-290.

Harper, D. B. 1993: Biogenesis and metabolic role of halomethanes in fungi and plants. Pp. 345-388 in Sigel, $\mathbf{H}$. \& Sigel, A. (eds.): Biological Properties of Metal Alkyl Derivates, vol. 29 of Metal Ions in Biological Systems. Marcel Dekker, New York.

Heath, C. W. \& Singleton, W. J. 1988: A device for remote sampling of benthic algae under ice. Hydrobiol. 165 , $169-171$.

Itoh, N., Izumi, Y. \& Yamada, H. 1987: Characterization of nonheme iron and reaction mechanism of bromoperoxidase in Corallina pilulifera. J. Biol. Chem. 262, 11982-11987.

Laturnus, F. 1993: Formation and release of low-molecular weight halogenated hydrocarbons by macroalgae from polar regions. Rep. Pol. Res. 132, Alfred Wegener Inst. Polar Marine Res., 188 pp. (German with English abstract).
Laturnus, F. 1996: Volatile halocarbons released from Arctic macroaigae. Mar. Chem. 55, 359-366.

Lüning, K. 1990: Seaweeds - Their Environment, Biogeogra phy and Ecophysiology. John Wiley and Sons, New York. 527 pp.

Mehrtens, G. 1994: Haloperoxidase activities in Arctic macroalgae. Polar Biol. 14, 351-354.

Moore, R. E. 1977: Volatile compounds from marine algae. Acc. Chem. Res. 10, 40-47.

Morris, D. \& Hager, L. 1966: Chloroperoxidase: isolation and properties of the crystalline glycoprotein. J. Biol. Chem. 241, 1763-1768.

Neidleman, S. L. \& Geigert, J. 1986: Biohalogenation Principles. Basic Roles and Applications. Ellis Horwood Series in Organic Chemistry, Market Cross House, England. 202 pp.

Peter, T. 1994: The stratospheric ozone layer - An overview. Environ. Pollut. 83, 69-79.

Soedjak, H. \& Butler, P. 1990: Characterization of vanadium bromoperoxidase from Macrocystis and Fucus: Reactivity of vanadium bromoperoxidase towards acryl and alkyl peroxides and bromination of amines. Biochem. 29, $7974-7981$.

Solomon, S. 1990: Progress towards a quantitative understanding of Antarctic ozone depletion. Nature (London) 347, 347-354.

Theiler, R., Cook, J. C., Hager, L. P. \& Siuda, J. F. 1978: Halohydrocarbon synthesis by bomoperoxidase. Science 202 , 1094-1096.

Walter, B. \& Ballschmiter, K. 1992: Formation of $\mathrm{C}_{1} / \mathrm{C}_{2}$ bromo-/chloro-hydrocarbons by haloperoxidase reactions. Fresen. J. Anal. Chem. 342, 827-833.

Wever, R., Tromp, M. G. M., Krenn, B. E., Marjani, A. \& Van Tol, M. 1991: Brominating activity of the seaweed Ascophyllum nodosum: Impact on the biosphere. Environ. Sci. Technol. 25, 446-449.

Vilter, H., Glombitza, K. W. \& Grawe, A. 1983: Peroxidases from Phaeophyceae. I. Extraction and detection of the peroxidases. Bot. Mar. 26, 331-340.

Yamada, H., Itoh, N., Murakami, S. \& Izumi, Y. 1985: New bromoperoxidase from Coralline algae that brominate phenol compounds. Agric. Biol. Chem. 49, 2961-2967. 
